\title{
Numerical discrimination by rats using sequential auditory stimuli
}

\author{
HANK DAVIS and MELODY ALBERT \\ University of Guelph, Guelph, Ontario, Canada
}

\begin{abstract}
Three rats were trained under a discrimination procedure in which responding was reinforced only following the repeated presentation of three bursts of white noise $(\mathrm{S}+)$. $\mathrm{S}-$ consisted of presentations of either two or four bursts of noise. All animals responded significantly more in the presence of S+ and, in two cases, showed lower response rates to both " 2 " and " 4 " stimuli. Responding by the third animal revealed differentiation between $\mathrm{S}+$ and the stimulus " 2 ," but no reliable suppression to stimulus " 4 ." The present instances of discriminative control by the stimulus “ 3 " replicate Fernandes and Church's (1982) demonstration of control by sequential auditory stimuli in the rat. Moreover, because the present procedure involves adjacent $\mathrm{S}-$ values both greater as well as less than $\mathrm{S}+$, these results extend our knowledge of the rat's abilities with sequential auditory stimuli: Rats are capable of making intermediate numerical discriminations based upon something other than a simple many-versus-few dichotomy.
\end{abstract}

Interest in the cognitive abilities of animals has undergone considerable development in the past decade (e.g., Hulse, Fowler, \& Honig, 1978; Roitblat, Bever, \& Terrace, 1984). Not surprisingly, there has been a corresponding interest in the ability of animals to "count" or make numerical discriminations (e.g., Church \& Meck, 1984; Davis \& Memmott, 1983). A recent review of the "counting" literature has revealed evidence of numerical abilities in a wide array of birds and mammals (Davis \& Memmott, 1982).

Most of the evidence for numerical skill in animals comes from procedures in which visual stimuli were presented simultaneously. Subjects are typically required to discriminate the number of items in the array and to use this information as the basis for their responses (e.g., Davis, 1984; Hicks, 1956). The outcomes of such experiments are not necessarily based upon counting. By their very nature, techniques involving the simultaneous presentation of visual stimuli may allow the animal to subitize. Subitizing has been described as the direct, perceptual apprehension of a small number of simultaneously presented items (Kauffman, Lord, Reese, \& Volkmann, 1949; Mandler \& Shebo, 1982). This process is typically contrasted to more cognitive abilities, such as counting, in which items are enumerated using a sequence of cardinal labels or tags (Gelman \& Gallistel, 1978; Koehler, 1950; Piaget, 1952).

In comparison with the use of simultaneous presentation techniques, the use of sequentially delivered events is considerably more rare. Nevertheless, such procedures

This research was supported in part by Grant $\mathrm{A06973}$ from the Natural Sciences and Engineering Research Council of Canada. The authors thank Rod Barron, Harry Hurwitz, and Rachelle Perusse for their thoughtful criticisms. Reprints may be obtained from the first author, c/o Department of Psychology, University of Guelph, Guelph, Ontario, Canada N1G 2W1. have yielded positive evidence of numerical discrimination in animals. By definition, the results of sequential techniques do not lend themselves to analysis in terms of simple perceptual mechanisms such as subitizing, but rather seem to require a more complex behavioral response involving both the storage and integration of information.

In addition to ruling out subitizing, sequential delivery techniques offer a further advantage to the study of number. By presenting items sequentially rather than simultaneously, it becomes possible to employ not only visual, but auditory stimuli as well. ${ }^{1}$ In perhaps the most comprehensive study of this nature, Fernandes and Church (1982) examined whether rats could discriminate the number of sequentially presented bursts of noise. Subjects were required to press the right lever whenever they heard two bursts of white noise, and the left lever whenever they heard four bursts of noise. Controls were established for the duration of each burst of noise, as well as the intervals between them, thus assuring that discrimination was based upon quantitative, rather than temporal or durational, attributes of the stimuli.

Although Fernandes and Church succeeded in establishing that rats can discriminate between sequential presentations of two and four bursts of noise, it is not clear that this discrimination was, in fact, based upon a numerical process. Rather, as the authors themselves note, it may be that the " 2 "'-versus-" 4 " discrimination represents a numerousness judgment. In short, rats may have learned to respond on the right lever whenever they heard "few" sounds and to respond on the left lever whenever they heard "many" sounds.

It has been argued that dichotomous judgments of relative numerousness may represent a primitive discriminative ability that bears no logical or developmental relation to numerical abilities (Davis, Albert, \& Barron, 1985; 
Stevens, 1951; Thomas, Fowlkes, \& Vickery, 1980). This is not to say that the rat is incapable of making more complex numerical discriminations on the basis of sequential auditory information. At the very least, it may be possible to employ a variant of the Fernandes and Church procedure in such a way as to require the rat to discriminate something other than a simple many-versus-few dichotomy.

The following experiment was performed to test the rat's ability to detect an intermediate number within a range of three adjacent numbers. Subjects were trained to leverpress on a fixed-interval (FI) schedule, and subsequently were reinforced for responding only in the presence of three brusts of white noise $(S+)$. Responding in the presence of either two or four bursts of noise $(S-)$ was not reinforced. As in the Fernandes and Church study, the duration of each burst of noise and the interval between bursts were varied in order to preclude discrimination based upon durational properties of the signals. Because $S$ - values consisted of adjacent numbers greater than as well as less than the value of $S+$, successful performance in the present experiment was based upon something other than a simple many-versus-few dichotomy.

\section{METHOD}

\section{Subjects}

Three female Long-Evans rats, food deprived to approximately $90 \%$ of their ad-lib weights, served as subjects. The animals were housed individually with water continuously available in their home cages. The subjects were approximately 100 days old at the start of training.

\begin{abstract}
Apparatus
The subjects were run in a commercially available operant test chamber (Lehigh Valley Electronics). Forty-five-milligram Noyes food pellets served as reinforcers. Auditory signals consisted of white-noise bursts generated by a Commodore 64 microcomputer and recorded directly onto a Sony open-reel tape recorder. Auditory signals were presented through a 2.5 -in.-diam speaker located behind the food magazine of the test chamber.

Each stimulus consisted of a burst of white noise. Stimulus length was set at either 0.2 or $0.5 \mathrm{sec}$, with an approximately equal proportion of cases under the " 2 ," " 3 ," and " 4 "' stimulus conditions. Interstimulus interval (ISI) was defined as the period of silence between each successive white-noise burst in the sequence. ISI durations were set at either 0.5 or $0.9 \mathrm{sec}$. Total sequence duration (TSD) was defined as the time from onset of the first stimulus in the sequence to the termination of the final ISI. TSDs for the " 2 "'-burst sequences were 2.0 and $2.4 \mathrm{sec}$. TSDs for the " 3 "'-burst sequences were $2.1,3.0$, and $4.2 \mathrm{sec}$. TSDs for the " 4 "'-burst sequences were 2.8 and $4.0 \mathrm{sec}$. Thus, there were occasions on which the overall duration of a " 2 "' sequence was longer than that of a " 3 "'; similarly, there were instances of " 3 " sequences with longer durations than " 4 " sequences. The interval between repetitions of the " 2 "', " 3 ", and " 4 " burst sequences remained constant at $4 \mathrm{sec}$.
\end{abstract}

\section{Procedure}

Subjects were individually placed in the operant test chamber and trained to leverpress for food. Initially, reinforcement was given according to a continuous reinforcement schedule. Following a maximum of six sessions, this was changed to a FI 1-min schedule of reinforcement.

When operant performance had stabilized, numerical discrimination training was begun. A sequence of two, three, or four bursts of white noise was repeated while the animal worked on each 1-min cycle of the FI schedule. Leverpressing was reinforced only in the presence of the " 3 " stimulus, that is, a leverpress was reinforced at the end of a 1-min FI cycle during which a sequence of three stimuli had been repeatedly presented. Leverpressing was not reinforced following FI cycles during which a repeated sequence of two or four sounds was presented. ${ }^{2}$ Following each FI cycle, there was a 10-sec time-out, during which chamber lights were turned off and no auditory signals were presented. The onset of the next 1-min FI cycle was marked by the reappearance of the houselights and the start of the next auditory sequence.

Each rat was run for a total of 52 daily sessions, each consisting of $60 \mathrm{FI}$ cycles. The pattern of numerical stimulus presentations was varied each day, and on any given trial the probability of a reinforced (i.e., " 3 "') trial was equal to that of a nonreinforced trial. Nonreinforced trials were signaled by repeated presentations of either the " 2 "'-sound or the " 4 "'-sound sequence. The likelihood of a " 2 " sequence was theoretically equal to that of a " 4 ," although, because of the relatively small number of trials in a single session, there was usually some disparity between the number of " 2 "-versus-" 4" sequences presented. However, the number of " 2 " and " 4 " sequences was approximately equal across all sessions.

\section{RESULTS}

An ANOVA performed on response rates in the presence of the three different numerical stimuli revealed a significant difference for all animals [Rat $1, F(2,18)=$ $30.02, p<.001$; Rat $2, F(2,18)=32.05, p<.001$; Rat 3, $F(2,18)=10.83, p<.001]$.

To determine whether this rate difference provided evidence for a numerical discrimination, post hoc comparisons were performed using a Dunn test. These data are illustrated in Figure 1. For Rat 1, the mean response rate in the presence of stimulus " 3 " was greater than that recorded during both stimulus " 2 " and stimulus " 4 ", (Dunn $p<.01$ ). There was no difference in the rate of responding during stimuli " 2 " and " 4 " for this animal.

The mean response rate for Rat 2 was also significantly higher in the presence of stimulus " 3 " than it was for either stimulus " 2 " or stimulus " 4 " ( $(p<.01)$, although there was also a difference between the two $S$ - values $(p<.01)$.

The final animal, Rat 3, also showed a significant elevation in response rate during stimulus value " 3 " relative to that of " 2 " ( $(p<.01)$, but the rate during stimulus " 3 " for this animal did not differ from that recorded in " $4 . "$

\section{DISCUSSION}

All animals showed significantly higher response rates in the presence of the reinforced " 3 "' stimulus. Insofar as the responding of Subjects 1 and 2 was suppressed to stimulus values both greater than and less than $S+$, it is clear that their discrimination of the three stimuli could not have been based upon a simple many-versus-few discrimination. Although Subject 3 was capable of discriminating between stimuli " 2 " and ' 3 ", this subject's " 3 "'-versus-" 4 " discrimination was not statistically reliable across sessions. This is consistent with the extension 

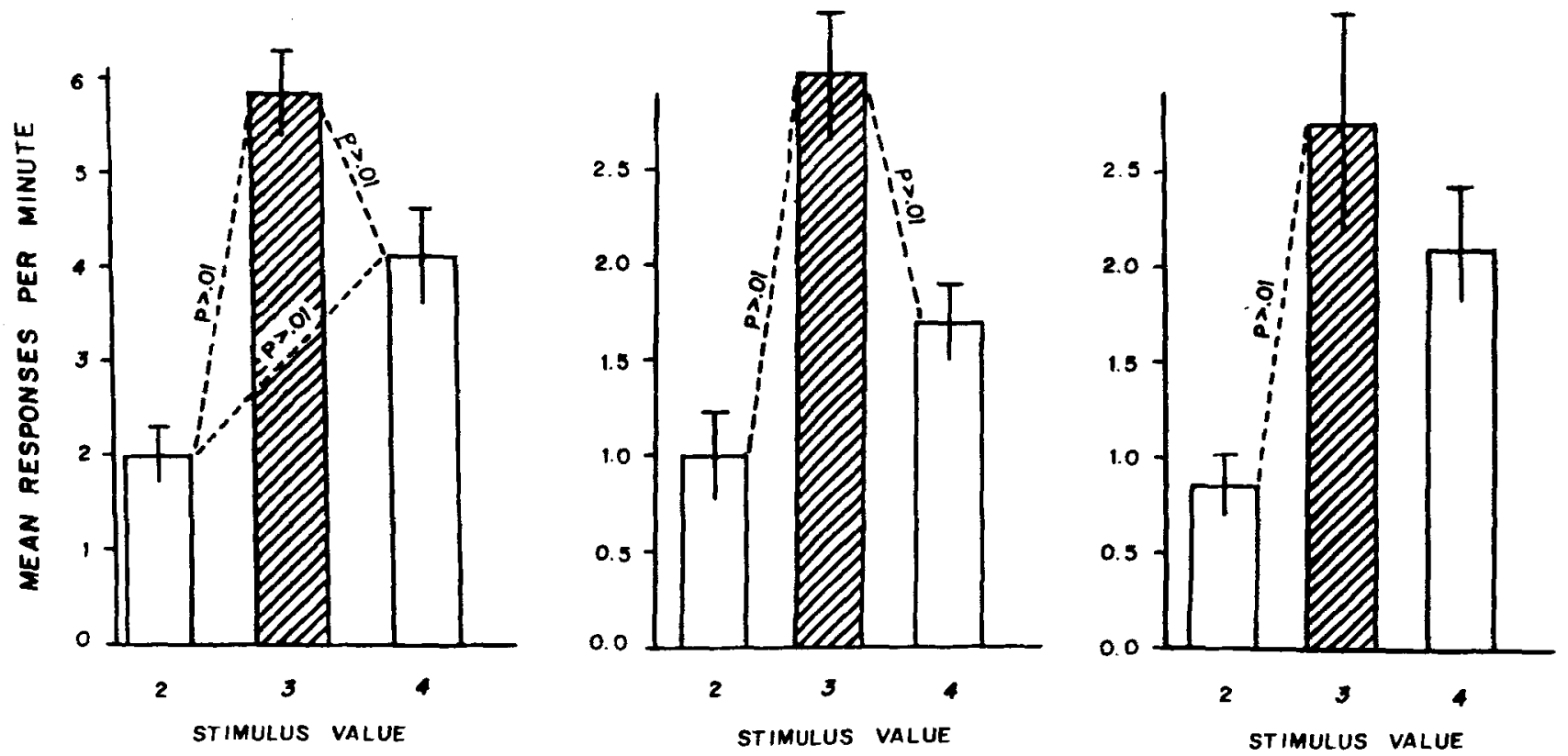

Figure 1. Response rates in the presence of each of three numerical stimuli presented in sequential auditory fashion. Data were obtained during the final 10 sessions for Rats 1, 2, and 3. Standard errors are indicated by vertical bars.

of Weber's law suggested by Seibt (1982), that is, detection of a 2-3 inequality is easier than one based upon 3-4, insofar as the former stems from a more salient $50 \%$ proportional increase versus only $33 \%$ in the latter case.

It is notable that virtually all previous work with numerousness estimations has involved simple dichotomous (many vs. few) situations. By adding a third quantity to discriminate, we have not necessarily demonstrated counting or precluded processing based upon numerousness in favor of absolute number. However, we believe that the level of processing required for an intermediate number task, especially one involving adjacent values, is different from that required for a simple many-versus-few discrimination. In conclusion, the present data, together with those reported by Fernandes and Church (1982), provide a fuller view of the rat's cognitive/numerical abilities.

\section{REFERENCES}

Сhurch, R. M., \& Meck, W. H. (1984). The numerical attribute of stimuli. In H. L. Roitblat, T. G. Bever, \& H. S. Terrace (Eds.), Animal cognition. Hillsdale, NJ: Erlbaum.

Davis, H. (1984). Discrimination of the number three by a raccoon (Procyon lotor). Animal Learning \& Behavior, 12, 409-413.

Davis, H., Albert, M., \& BARron, R. W. (1985). Detection of number or numerousness by human infants. Science, 228, 1222.

Davis, H., Memmotr, J. (1982), Counting behavior in animals: A critical evaluation. Psychological Bulletin, 92, 547-571.

Davis, H., MEMmotT, J. (1983). Autocontingencies: Rats count to three to predict safety from shock. Animal Learning \& Behavior., 11, 95-100.

Fernandes, D. M. \& ChURCH, R. (1982). Discrimination of the number of sequential events by rats. Animal Leaming \& Behavior, 10, 171-176.

GelmaN, R., \& GAllistel, C. R. (1978). The child's understanding of number. Cambridge, MA: Harvard University Press.

Hicks, L. H. (1956). An analysis of number-concept formation in the thesus monkey. Joumal of Comparative \& Physiological Psychology, 49, 212-218.
Hulse, S. H., Fowler, H., HONIG, W. K. (1978). Cognitive processes in animal behavior. Hillsdale, NJ: Erlbaum.

Kaufman, E. L., Lord, M. W., Reese, T. W., \& VolkmanN, J. (1949). The discrimination of visual number. American Journal of Psychology, 62, 498-525.

KoenLer, O. (1950). The ability of birds to "count." Bulletin of Animal Behaviour, 9, 41-45.

Mandler, G., \& Shebo, B. J. (1982). Subitizing: An analysis of its component processes. Joumal of Experimental Psychology: General, $111,1-22$

PIAGET, J. (1952). The child's conception of number. London: Routledge \& Kegan Paul

Roitblat, H. L., Bever, T. G., \& Terrace, H. S. (Eds.) (1984). Animal cognition. Hillsdale, NJ: Erlbaum.

SEIBT, U. (1982). Zahlbegriff und Zahlverhalten bei Tieren. Neue Versuche und Deutungen. Zeitschrift für Tierpsychologie, 60, 325-341.

STEVENS, S. S. (1951). Mathematics, measurement, and psychophysics. In S. S. Stevens (Ed.), Handbook of experimental psychology. New York: Wiley.

Thomas, R. K., Fowlkes, D., \& Vickery, J. D. (1980). Conceptual numerousness judgments of squirrel monkeys. American Journal of Psychology, 93, 247-257.

\section{NOTES}

1. Although it is possible to train a discrimination based upon the simultaneous presentation of auditory stimuli, such a procedure would presumably have to employ sounds of different frequencies, thus changing the focus of the study to the discrimination of tonalities or musical chords, rather than number, per se.

2. A limited-hold requirement was imposed under which reinforcement remained available for only $5 \mathrm{sec}$ following completion of the fixed interval. The animal's first leverpress, reinforced or otherwise, terminated the limited-hold period. If a response was not made during the limited hold, food was not delivered and the next FI cycle went into effect. Both reinforced and nonreinforced FI cycles were followed by the limited hold in order to preclude discrimination based solely upon the occurrence of this 5-sec period. Auditory signals were suspended during the limited hold.

(Manuscript received November 18, 1985; revision accepted for publication December 17, 1985.) 